\title{
Attentional capture in serial audiovisual search tasks
}

\author{
Polly Dalton \\ Royal Holloway University of London, London, England \\ AND \\ Charles Spence \\ University of Oxford, Oxford, England
}

\begin{abstract}
The phenomenon of attentional capture has typically been studied in spatial search tasks. Dalton and Lavie (2004) recently demonstrated that auditory attention can also be captured by a singleton item in a rapidly presented tone sequence. In the experiments reported here, we investigated whether these findings extend cross-modally to sequential search tasks using audiovisual stimuli. Participants searched a stream of centrally presented audiovisual stimuli for targets defined on a particular dimension (e.g., duration) in a particular modality. Task performance was compared in the presence versus absence of a unique singleton distractor. Irrelevant auditory singletons captured attention during visual search tasks, leading to interference when they coincided with distractors but to facilitation when they coincided with targets. These results demonstrate attentional capture by auditory singletons during nonspatial visual search.
\end{abstract}

The ability to focus attention selectively on certain stimuli at the expense of others is important for everyday cognitive functioning. However, it is also important that focused attention can be interrupted by stimuli that are likely to signal an unexpected (and potentially important) change in the environment. The phenomenon of attentional capture, in which focused attention is interrupted by the presence of certain types of distracting stimuli, has been the focus of much unimodal visual and auditory attention research (e.g., Dalton \& Lavie, 2004; Folk, Leber, \& Egeth, 2002; Jonides \& Yantis, 1988; Theeuwes, 1992). However, studies investigating attentional capture between different sensory modalities are much less common and have tended to focus exclusively on spatial capture (or cuing) effects (see Spence, 2001, for a review). In the present study, we investigated the possibility of nonspatial attentional capture between vision and audition, using sequential search tasks.

Until recently, attentional capture research has tended to focus on the effect as demonstrated within spatial visual search arrays. In a typical experimental design, participants have been asked to search an array of spatially distributed visual items for a target defined on a particular dimension (e.g., with a particular shape). The now well-established finding has been that attention can be captured during this type of spatial visual search by unique singletons (e.g., items with a unique color, or items that appear with an abrupt onset when the other items onset gradually), even when these singletons are unique on a dimension that is never relevant to the participants' task (e.g., Jonides \& Yantis, 1988; Pashler, 1988; Theeuwes, 1992). ${ }^{1}$

However, more recently, researchers have begun to ask whether attentional capture can also occur during sequential search tasks, in which items are presented one after another. Research on the attentional blink (AB) has demonstrated that allocation of attention to a first target item in a rapidly presented stream of stimuli can impair processing of subsequent targets in the stream (e.g., Raymond, Shapiro, \& Arnell, 1992). However, because the participants in these studies were explicitly asked to attend to the first target, the results of $\mathrm{AB}$ experiments are not directly relevant with regard to the possibility of attentional capture by task-irrelevant items in sequential streams. Nevertheless, there is evidence that under some circumstances, unique yet task-irrelevant items in the $\mathrm{AB}$ design (e.g., a colored box around a nontarget letter) can interfere with the recall of a subsequent target, suggesting that the singleton item may attract attention despite its being irrelevant to the participants' task (e.g., Chun, 1997; Folk, Leber, \& Egeth, 2001; Maki \& Mebane, 2006; Wee \& Chua, 2004). Note, however, that reliable effects in these studies were elicited only by singleton items that were defined on the same dimension as the targets (e.g., they were both color singletons). The results may, therefore, reflect deliberate attentional allocation toward these singletons because they possess a task-relevant feature.

By contrast, Dalton and Lavie (2006) recently showed attentional capture during a rapid serial visual presentation

P. Dalton, polly.dalton@rhul.ac.uk 
(RSVP) size discrimination task by singletons defined on the task-irrelevant dimension of color, demonstrating that visual attentional capture by task-irrelevant singletons can be found in sequential search arrays. Because this kind of attentional capture involves attentional allocation toward an item that is separated in time (rather than in space) from the other search items, we have termed it temporal attentional capture, to distinguish it from spatial versions of the effect. Similar findings have emerged from studies of audition. For example, Dalton and Lavie (2004) found temporal attentional capture by irrelevant auditory feature singletons in auditory detection and discrimination tasks in which sequentially presented stimuli were used. Thus, there is evidence from unimodal visual and auditory studies that irrelevant singletons can capture attention during sequential search tasks.

In the present study, we investigated the possibility of cross-modal attentional capture by irrelevant singletons in sequential audiovisual search tasks. Although this possibility has not yet been addressed, previous research has demonstrated that under certain conditions, the allocation of attention to an item in one modality can impair the processing of a subsequent item presented in a different modality. For example, some cross-modal AB studies have suggested that attentional allocation to a stimulus in one sensory modality can lead to an $\mathrm{AB}$ for a stimulus in a different modality (e.g., Arnell \& Jenkins, 2004; Arnell \& Jolicœur, 1999; Arnell \& Larson, 2002; Soto-Faraco et al., 2002). Note, however, that the evidence in this area is fairly mixed, with other studies showing no evidence to support the existence of a cross-modal AB (e.g., Duncan, Martens, \& Ward, 1997; Potter, Chun, Banks, \& Muckenhoupt, 1998; Soto-Faraco \& Spence, 2002; see also Arnell $\&$ Duncan, 2002). In any case, since the AB research assesses the consequences of the deliberate allocation of attention to sequentially presented targets, it cannot speak to the present issue of attentional capture by task-irrelevant singletons.

There is, however, further evidence to suggest that the presentation of auditory deviants can interfere with behavioral performance in a subsequent visual task. For example, Escera, Alho, Winkler, and Näätänen (1998) showed that responses in a visual (odd vs. even number) discrimination task were less accurate when the number stimulus followed a sound of deviant frequency than when it followed a standard frequency sound. Similar effects have been found following the presentation of intensity and duration deviants (e.g., Escera, Corral, \& Yago, 2002). However, it is important to note that the auditory stimuli used in these studies predicted the target event, and the slow rates of stimulus presentation used meant that the overall demands on attentional resources were low. Taken together, these factors mean that there was little incentive for the participants to attempt to ignore the auditory distractors in these studies (indeed, the fact that the deviants tended to predict the target should, if anything, have encouraged the participants to pay attention to them), and as such, the results may be attributable to voluntary allocation of attention to the auditory stimuli, rather than to involuntary capture of attention by those stimuli.
There is also evidence that auditory deviants can cause facilitation in simultaneous visual tasks. For example, the participants in a study by Vroomen and de Gelder (2000, Experiment 1) had to search a rapidly presented repeating sequence of four masked dot patterns for a target pattern (four dots arranged in a diamond shape) and had to indicate the corner of the screen in which the target diamond appeared. On half of the trials, each visual pattern was accompanied by a standard low-frequency tone. On the other half of the trials, nontarget visual patterns were accompanied by the standard, whereas the visual target was accompanied by a high-frequency tone. Responses were quicker and more accurate in the latter condition than in the condition in which the target was accompanied by a tone of the same frequency as that for the nontargets. This finding suggests that auditory perceptual organization processes (which would have been expected to group the odd-one-out high-frequency tone separately from the lower frequency standard tones) influenced visual perception, facilitating the processing of the visual stimulus that occurred at the same time as the high-frequency tone (see Watanabe \& Shimojo, 2001, for a similar demonstration involving ambiguous visual motion judgments; see Spence, Sanabria, \& Soto-Faraco, 2007, for a review). However, the odd-one-out auditory tones that facilitated visual perception in these experiments always coincided with the visual target. Thus, there was no incentive for the participants to ignore the singleton stimuli (and in fact, there may have been good reason for the participants to attend to them). These results, therefore, cannot be characterized in terms of involuntary attentional capture by the singletons. They are, nevertheless, promising in suggesting that the auditory singletons in the present study might be expected to affect visual discrimination performance.

In the experiments reported here, we used sequential search tasks in which several audiovisual stimuli were presented one after another from the same location to form a search stream. In Experiment 1, we assessed whether auditory duration singletons (i.e., stimuli that are unique on the dimension of duration) would capture attention during a visual duration search task and whether visual duration singletons would capture attention during an auditory duration search task. In Experiments 2, 3, and 4, we focused on the effects of auditory singletons on visual search tasks. These experiments were designed to replicate the effects of Experiment 1 and also to determine whether auditory frequency singletons could capture attention during visual duration tasks (Experiment 2) and whether auditory duration singletons could capture attention during visual size discrimination tasks (Experiments 3 and 4).

\section{EXPERIMENT 1}

In this experiment, we investigated whether irrelevant singletons would produce temporal attentional capture in a sequential auditory or visual search task. Participants searched sequences of four centrally presented visual stimuli (white squares), each of which was accompanied by a simultaneous auditory tone. They were asked to pay attention, in different blocks of trials, either to the auditory 
or to the visual stimuli. Regardless of the target modality, the participants' task was to identify targets whose duration was different from those of the other (nontarget) stimuli and to make a speeded discrimination response regarding the target's duration (longer or shorter than the other stimuli). On a subset of trials, one of the stimuli in the irrelevant sensory modality was unique on the dimension of duration. ${ }^{2}$ We assessed performance as a function of whether this singleton was absent, present at the same point in the stream as the target, or present at a different point in the stream. If the singleton captures attention, we might expect to see a facilitation of responses on trials on which it coincided with the target (since attention should be drawn toward the target item) but an interference with responses on trials on which it coincided with a nontarget (since attention should then be drawn toward an irrelevant item).

\section{Method}

Participants. The participants in all four experiments were between 18 and 35 years of age and received a £5 (U.K. Sterling) gift voucher in return for their participation. All reported normal or corrected-to-normal vision and normal hearing. Twenty-six participants took part in Experiment 1, of which 13 were male and 25 were right-handed.

Stimuli and Procedure. The experiments were programmed and run on a PC using E-Prime (Psychology Software Tools, Pittsburgh). Each trial started with a blank screen presented for $300 \mathrm{msec}$. Four white squares were then presented (against a black background) one after another at the center of the screen. The "squares" subtended a visual angle of $1.4^{\circ}$ horizontally and $1.3^{\circ}$ vertically, at a viewing distance of $60 \mathrm{~cm}$. Each square was accompanied by a simultaneous $440-\mathrm{Hz}$ auditory stimulus, presented from a loudspeaker placed directly behind the center of the screen (so that the auditory and the visual stimuli were presented from approximately the same spatial location).
The participants were instructed to monitor the auditory stimuli or the visual stimuli in alternating blocks of trials. The order of the blocks (visual vs. auditory first) was counterbalanced across participants. Regardless of the modality to be attended, the targets were defined by their duration. Short targets had a duration of $50 \mathrm{msec}$, long targets a duration of $400 \mathrm{msec}$, and nontargets an intermediate duration of $150 \mathrm{msec}$. These durations were chosen for maximum discriminability between targets and nontargets, as verified by pilot testing. Each visual stimulus was presented along with its accompanying auditory stimulus, and these were followed by a random jitter interval inserted to prevent duration judgments from being made on the basis of some cue derived from the interstimulus intervals, rather than on the basis of the stimuli themselves. The item-to-item stimulus onset asynchrony (SOA) (including stimulus presentation and jitter interval) lasted for 500-850 msec. Figure 1 shows a schematic representation of an example trial from Experiment 1.

A target appeared on every trial in any one of the four serial positions with equal probability and was just as likely to be long as short. Irrelevant singletons, when they were presented, were also unique on the dimension of duration (with the same values as short and long targets, described above) but were presented in the irrelevant nontarget modality. They appeared on $80 \%$ of the trials, in any one of the four serial positions with equal probability and long or short with equal probability. Thus, on $20 \%$ of the trials, the singleton and the target would appear at the same point in the sequence (these are referred to as singleton target trials). On a further $60 \%$ of the trials, the singleton appeared at the same point in the sequence as a nontarget (these are referred to as singleton distractor trials). The singleton was absent on the remaining $20 \%$ of the trials. Note that the presence and temporal location of the singleton had no predictive value with regard to the likely location of the target stimulus within the stream (hence, there was absolutely no strategic reason for the participants to attend to the singleton).

The participants were instructed to respond as soon as they had identified a target. Half of the participants pressed the " $z$ " key on the computer keyboard for short targets and the " $m$ " key for long targets, using the index fingers of the left and right hands, respectively. The

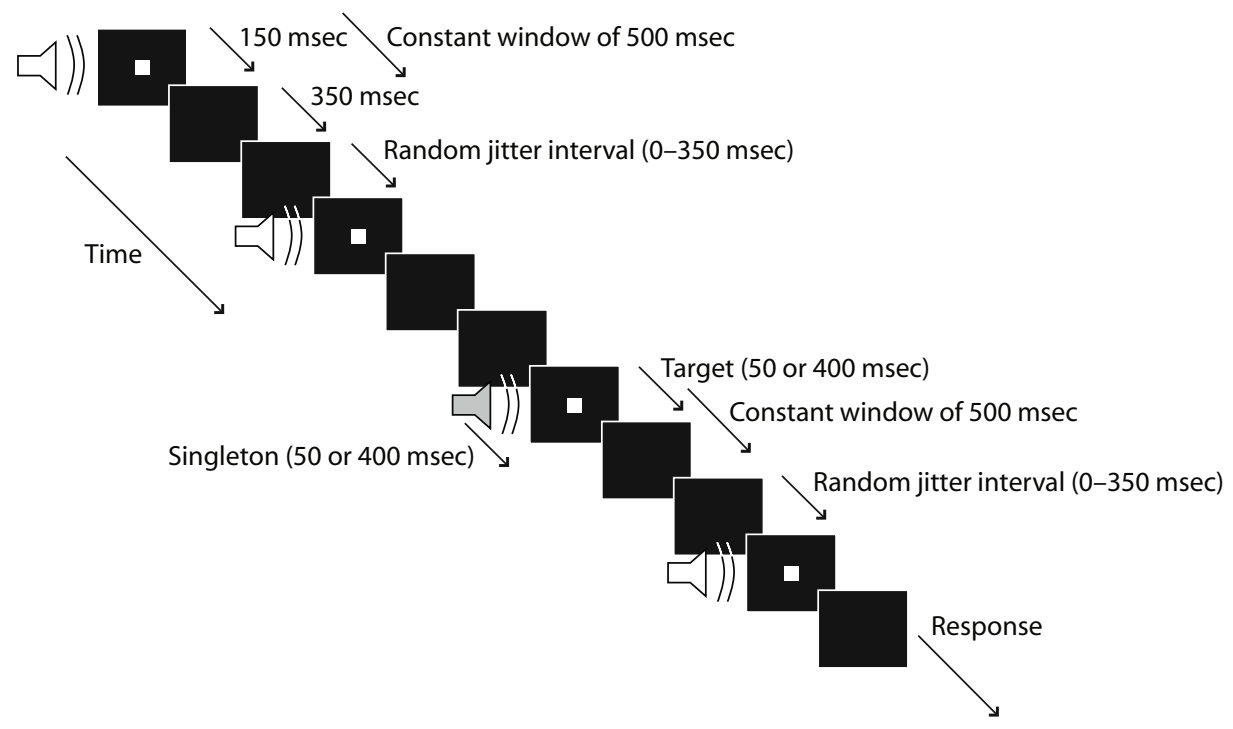

Figure 1. Schematic representation of a typical trial from Experiment 1. The figure shows an attend-vision trial, in which the auditory singleton coincides with the visual target. This type of trial made up $20 \%$ of the trials in total. The participants were presented with four audiovisual stimuli, one after another, with auditory and visual stimuli presented from the same spatial location. The stimuli varied in duration, with nontargets lasting $150 \mathrm{msec}$ and targets and singletons lasting 50 or 400 msec. The item-to-item stimulus onset asynchrony (including stimulus presentation and a random jitter interval) lasted for $\mathbf{5 0 0 - 8 5 0 ~ m s e c . ~}$ 
other half used the same fingers on the same keys but pressed " $m$ " for short targets and " $z$ " for long targets. Feedback was provided following incorrect or missed responses (i.e., trials on which the participant had not responded within 2,000 msec of the end of the stream). The feedback screen displayed either the word incorrect or the word missed (in red against a black background) for 1,000 msec and was accompanied by a short $(100-\mathrm{msec})$ low-frequency $(180-\mathrm{Hz})$ tone. Following correct responses, an empty black screen was presented for $1,000 \mathrm{msec}$, in place of the feedback screen. The participants were reminded of the sensory modality to which they should be attending at the start of each block of trials and were asked to ignore the stimuli presented in the irrelevant modality as much as possible. They were informed that their performance might be harmed if they failed to ignore these distractors. Two short practice blocks (one attend vision and one attend audition), each containing 15 trials, preceded four blocks of experimental trials (two attend vision and two attend audition), each containing 80 trials.

For a subset of 8 participants, the first author verified that they kept their eyes open even during the auditory blocks, using an infrared camera connected to a TV monitor situated outside the testing booth. This online monitoring also confirmed that all of these participants maintained roughly central fixation throughout. The camera (accompanied by an infrared light source) was placed directly above the computer screen and pointed at the participant's eye area.

\section{Results}

Figure 2 presents the mean response times (RTs; measured from the onset of the target) and error rates from Experiment 1 as a function of singleton condition (singleton absent, singleton target, or singleton distractor) for attend-vision blocks (panel A) and attend-audition blocks (panel B). In all of the experiments, incorrect responses were excluded from the RT analysis, as were RTs longer than 2,000 msec after the end of the sequence $(<2 \%$ of the trials). Because of the small number of observations in this preliminary experiment, the data are pooled across singleton type (long vs. short) and target type (long vs. short).

Attend vision. A two-way mixed model ANOVA was run on the RT data from the attend-vision blocks, using the within-participants factor of singleton condition (singleton absent, singleton target, or singleton distractor) and the between-participants factor of eye monitoring (monitored vs. unmonitored). The ANOVA revealed a significant effect of singleton condition $\left[F(2,48)=16.77, M S_{\mathrm{e}}=\right.$ $11,016.81, p<.01] . F$ contrasts revealed a significant facilitation effect of the auditory duration singleton in the visual duration discrimination task, so that responses were faster when the singleton coincided with the target $(M=$ $1,031 \mathrm{msec})$ than when it was absent $(M=1,202 \mathrm{msec})$ $\left[F(1,24)=21.50, M S_{\mathrm{e}}=29,992.18, p<.01\right]$. However, there was no interference effect (singleton absent vs. singleton distractor) of the auditory singletons in the visual task $(F<1)$. Importantly, there was no main effect of eye monitoring, and this factor did not interact with singleton condition ( $F<1$ for both comparisons), indicating that the participants performed similarly regardless of whether or not they were having their eye position monitored.

A similar ANOVA performed on the error data from the attend-vision blocks revealed a significant main effect of singleton condition $\left[F(2,48)=22.34, M S_{\mathrm{e}}=0.002\right.$, $p<.01]$. As with the RT data, $F$ contrasts revealed a significant facilitation effect (singleton absent vs. singleton target), so that error rates were lower when the auditory
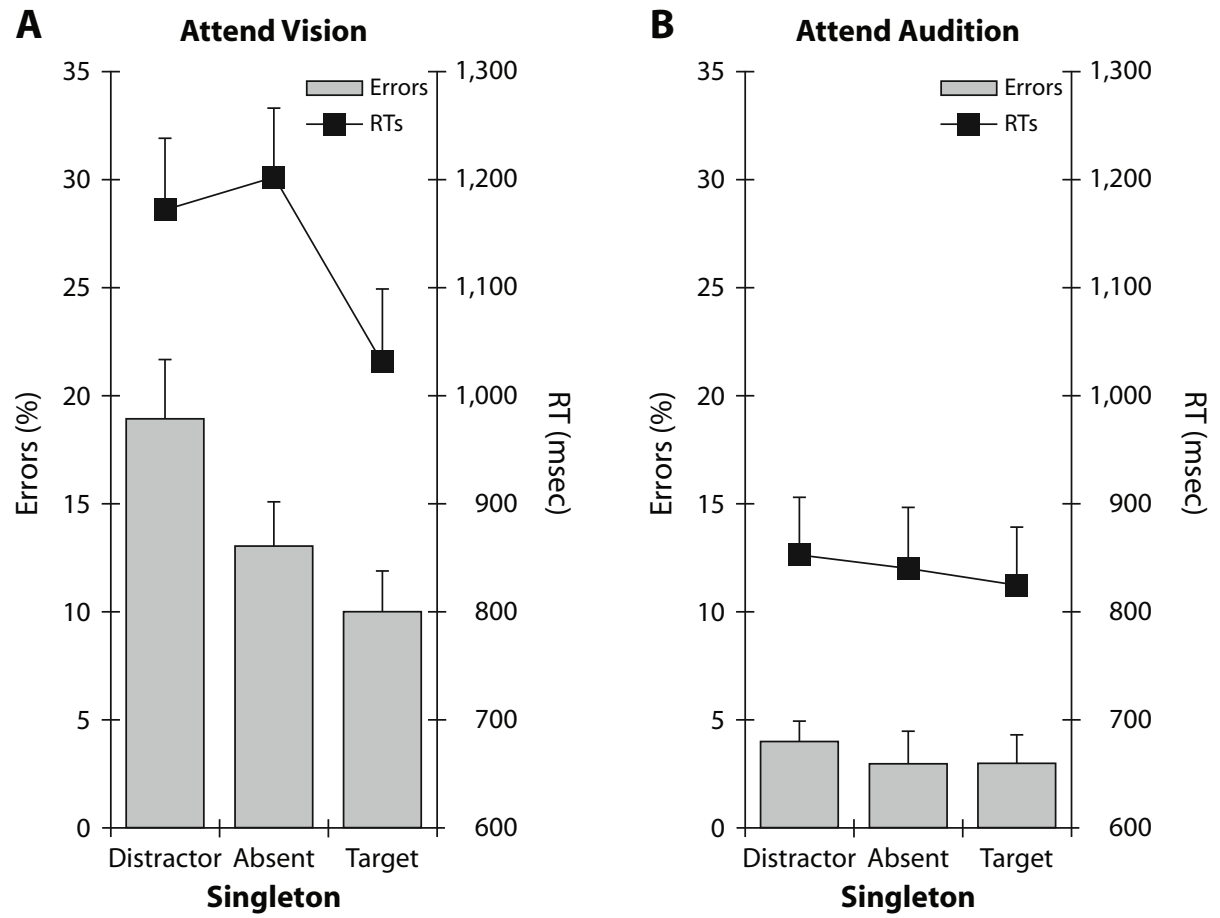

Figure 2. Mean response times (RTs; shown in line graphs) and error rates (shown in bar graphs) from Experiment 1 as a function of singleton condition (singleton distractor, singleton absent, or singleton target) in the attend-vision condition (A) and the attend-audition condition (B). Error bars represent the standard errors of the means. 
singleton coincided with the visual target $(M=10 \%)$ than when it was absent $(M=13 \%)\left[F(1,24)=8.36, M S_{\mathrm{e}}=\right.$ $0.004, p<.01]$. There was also a significant interference effect $\left[F(1,24)=14.19, M S_{\mathrm{e}}=0.006, p<.01\right]$, so that error rates were higher when the auditory singleton coincided with a visual distractor $(M=19 \%)$ than when it was absent $(M=13 \%)$. As for the RT data, there was no main effect of eye monitoring $(F<1)$, and this factor did not interact with singleton condition $(F=1)$, suggesting that the participants performed similarly regardless of whether or not they were having their eye movements monitored.

Overall, the results show facilitation effects (as indicated by shorter RTs and lower error rates) and interference effects (as shown by higher error rates) in the visual discrimination task associated with duration singletons presented in a completely task-irrelevant modality (see Figure 2A). This provides preliminary evidence for crossmodal attentional capture by such auditory singletons.

Attend audition. A two-way mixed model ANOVA on the RT data from the attend-audition blocks, with the within-participants factor of singleton condition and the between-participants factor of eye monitoring, showed no main effect of singleton condition $[F(1.5,35.6)=1.58$, $\left.M S_{\mathrm{e}}=3,453.24, p=.22\right]$. (Greenhouse-Geisser corrections were carried out on the degrees of freedom for this comparison, since Mauchly's test indicated that the sphericity assumption had been violated. Throughout this article, similar corrections will be made for all comparisons for which the sphericity assumption was violated.) As in the previous analyses, there was no main effect of eye monitoring, and this factor did not interact with singleton condition $(F<1$ for both comparisons). A similar ANOVA on the error data from attend-audition blocks showed no significant effects or interactions ( $p>.25$ for all comparisons).

Overall, the visual singletons presented in the attendaudition condition failed to produce significant effects in either the RT or the error data (see Figure 2B). By contrast, the auditory singletons presented in the attend-vision condition produced significant facilitatory and interference effects. The difference between these two patterns of results will be investigated further below.

Comparison between attend conditions. A further three-way mixed model ANOVA was run on the RT data to compare singleton effects between the attend-vision and the attend-audition conditions. This ANOVA used the withinparticipants factors of target modality (vision vs. audition) and singleton condition (singleton absent, singleton target, or singleton distractor) and the between-participants factor of eye monitoring. The analysis revealed a significant interaction between target modality and singleton condition $\left[F(1.5,36.9)=9.69, M S_{\mathrm{e}}=9,694.54, p<.01\right]$. This indicated that the significant singleton effects caused by the auditory singletons in the attend-vision condition were significantly larger than the null effects associated with the visual singletons in the attend-audition condition. $F$ contrasts indicated that the interaction occurred because of a significant difference in facilitation effects between the two conditions $\left[F(1,24)=11.91, M S_{\mathrm{e}}=22,556.35\right.$, $p<.01]$ and was not due to any difference in interfer- ence effects $\left[F(1,24)=1.37, M S_{\mathrm{e}}=13,536.21, p=\right.$ .25]. The ANOVA also showed a significant main effect of target modality $\left[F(1,24)=60.00, M S_{\mathrm{e}}=48,254.39\right.$, $p<.01$ ], so that RTs were shorter in response to auditory targets $(M=840 \mathrm{msec})$ than in response to visual targets $(M=1,136 \mathrm{msec})$. As in the previous analyses, there was no main effect of eye monitoring, and this factor did not interact with any of the other factors $(F<1$ for all comparisons).

A similar ANOVA was conducted on the error data. This also revealed a significant interaction between target modality and singleton condition $\left[F(2,48)=15.56, M S_{\mathrm{e}}=\right.$ $0.002, p<.01] . F$ contrasts indicated that singleton effects were significantly reduced in the attend-audition condition as compared with the attend-vision condition, in terms of both interference effects $[F(1,24)=11.57$, $\left.M S_{\mathrm{e}}=0.004, p<.01\right]$ and facilitation effects $[F(1,24)=$ $\left.5.34, M S_{\mathrm{e}}=0.004, p<.05\right]$. Also in line with the RT data, the ANOVA on the error data revealed a significant main effect of target modality $\left[F(1,24)=40.08, M S_{\mathrm{e}}=\right.$ $0.003, p<.01]$, indicating that error rates were higher overall in the attend-vision condition $(M=14 \%)$ than in the attend-audition condition $(M=3 \%)$. Lastly, as in all the previous analyses, there was no main effect of eye monitoring $(F<1)$, and this factor did not interact with any of the other factors ( $p>.25$ for all comparisons).

\section{Discussion}

The results of Experiment 1 demonstrated a facilitatory effect when auditory singletons coincided with visual targets (see Vroomen \& de Gelder, 2000, Experiment 1, for similar results), as well as revealing interference effects when auditory singletons coincided with visual distractors. This pattern of results is suggestive of an attentional capture effect by irrelevant auditory singletons in a sequential visual search task. By contrast, no such effects were found when irrelevant visual singletons appeared during a sequential auditory search task. This finding is perhaps unsurprising, given that audition is known to be dominant over vision in tasks involving temporal judgments (e.g., Walker \& Scott, 1981; Welch, DuttonHurt, \& Warren, 1986).

A subset of participants had their eye movements monitored while they carried out the task, in order to verify that they kept their eyes open even during attend-audition blocks. This group performed in a manner that was indistinguishable from that of the main group of participants (whose eye movements were not monitored), suggesting that the observed difference in singleton effects between auditory and visual singletons cannot be explained in terms of the participants' simply closing their eyes during the attend-audition blocks.

It is nevertheless possible that the reduced effects in the attend-audition condition were due to the apparent ease of the auditory task (recall that significantly better performance was observed in the attend-audition condition than in the attend-vision condition in both the RT and the error data). The possibility that attentional capture by visual singletons might be found using the present design if the auditory task were made more difficult remains a po- 
tentially interesting question for future research (see Arnell \& Duncan, 2002, and Spence, Ranson, \& Driver, 2000, for demonstrations of task demands' modulating cross-modal attentional effects). However, the focus of the following experiments was on the significant effects of auditory singletons in the attend-vision conditions, already observed.

\section{EXPERIMENT 2}

Experiment 2 was designed to investigate whether the attentional capture by auditory singletons demonstrated in Experiment 1 was contingent on singletons and targets being defined on the same dimension (recall that both were defined in terms of duration in Experiment 1). The participants in Experiment 2 carried out the same visual duration discrimination task as that used in Experiment 1, but now the auditory singletons were defined either by their duration (as in Experiment 1) or by their frequency.

\section{Method}

Participants. Eighteen new participants took part in this experiment. The data from 1 participant were not analyzed, due to chancelevel performance. Of the remaining 17 participants, 9 were male and 13 were right-handed.

Stimuli and Procedure. The stimuli and procedure were similar to those in Experiment 1, with the following exceptions. The participants carried out the visual duration search task throughout the experiment. Nontarget auditory stimuli had frequencies of $480 \mathrm{~Hz}$. Auditory singletons were defined either by their duration (as in Experiment 1) or by their frequency, in which case the high-frequency singletons were presented at $520 \mathrm{~Hz}$ and the low-frequency single- tons at $440 \mathrm{~Hz}$. Singleton type (duration or frequency) was blocked. Two short practice blocks, each containing 15 trials (one block with duration singletons and one with frequency singletons), preceded six experimental blocks, each containing 80 trials (three blocks with duration singletons alternating with three blocks with frequency singletons), with order of presentation (duration vs. frequency first) counterbalanced across participants.

\section{Results}

Figure 3 presents the mean RTs and error rates for duration singletons (panel A) and frequency singletons (panel B) as a function of singleton condition (singleton absent vs. singleton target vs. singleton distractor).

Duration singletons. As a consequence of the increased number of observations obtained in the present experiment (in comparison with Experiment 1), singleton effects in duration singleton blocks could now be assessed in terms of target-singleton congruency (when the targets and the singletons are both long or both short, they are congruent, whereas when the targets and the singletons have different durations, they are incongruent). ${ }^{3}$ Table 1 presents the mean RTs and error rates for duration singleton blocks as a function of singleton condition/congruency (singleton absent vs. singleton target [congruent] vs. singleton target [incongruent] vs. singleton distractor [congruent] vs. singleton distractor [incongruent]).

A two-way within-participants ANOVA was conducted on the RT data from the duration singleton blocks, using the factors of singleton condition/congruency (singleton absent vs. singleton target [congruent] vs. singleton target [incon-
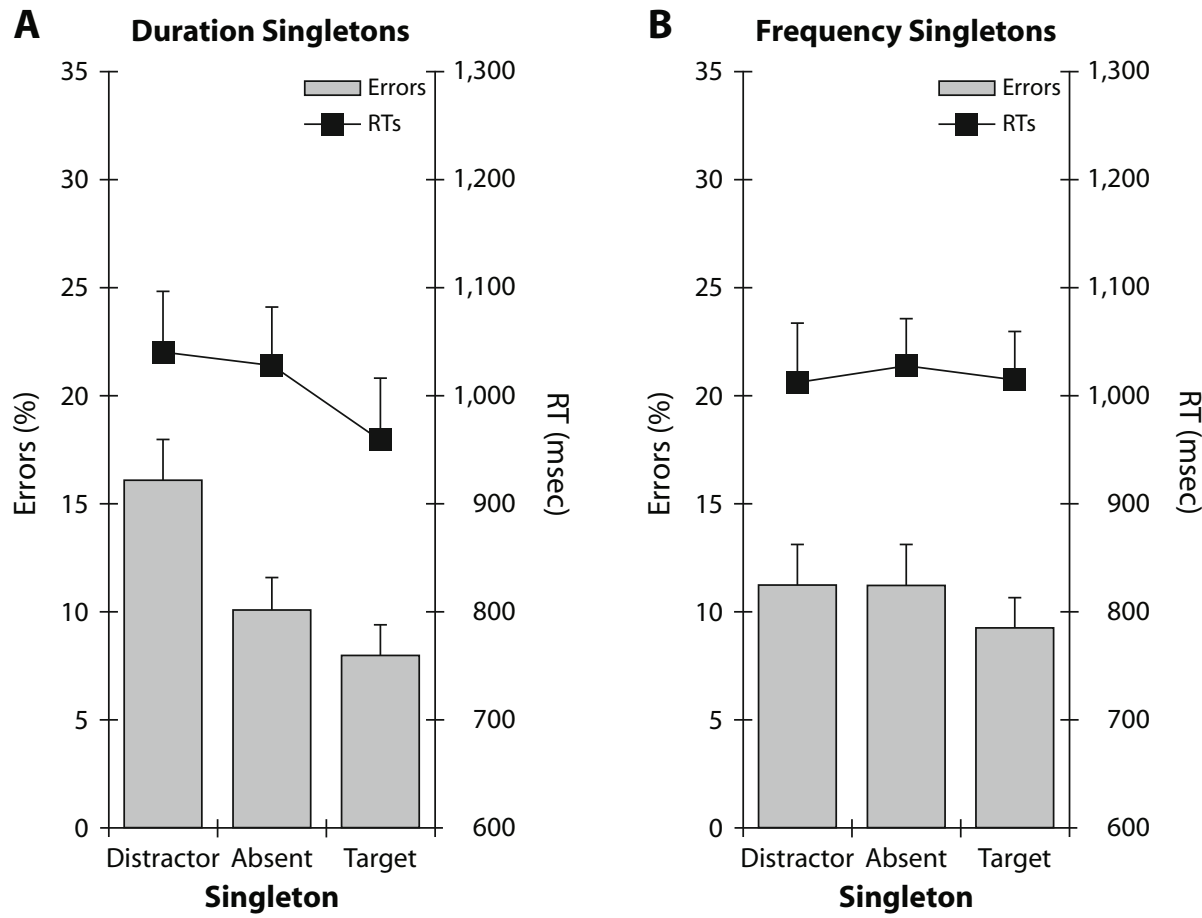

Figure 3. Mean response times (RTs; shown in line graphs) and error rates (shown in bar graphs) from Experiment 2 as a function of singleton condition (singleton distractor, singleton absent, or singleton target) in the duration singleton condition (A) and the frequency singleton condition (B). Error bars represent the standard errors of the means. 
Table 1

Averages of Participants' Mean Response Times (RTs, in Milliseconds, With Standard Errors) and Mean Error Rates (in Percentages) for Duration Singleton Blocks in Experiment 2 As a Function of Singleton Condition

\begin{tabular}{crcc}
\hline Condition & RT & $S E$ & \%Error \\
\hline Singleton absent & 1,026 & 53 & 10 \\
Singleton target & & & \\
Congruent & 969 & 54 & 7 \\
Incongruent & 950 & 61 & 9 \\
Singleton distractor & & & \\
$\quad$ Congruent & 1,050 & 58 & 13 \\
Incongruent & 1,030 & 58 & 18 \\
\hline
\end{tabular}

gruent] vs. singleton distractor [congruent] vs. singleton distractor [incongruent]) and target type (long vs. short). As in Experiment 1, this analysis revealed a significant main effect of singleton condition/congruency $[F(4,64)=$ $\left.6.51, M S_{\mathrm{e}}=9,679.33, p<.01\right] . F$ contrasts revealed significant facilitation effects (singleton target vs. singleton absent) for congruent singletons $\left[F(1,16)=11.75, M S_{\mathrm{e}}=\right.$ $9,188.29, p<.01]$, as well as for incongruent singletons $\left[F(1,16)=9.47, M S_{\mathrm{e}}=20,559.41, p<.01\right]($ see Table 1$)$. As in Experiment 1, there were no significant interference effects, for either congruent or incongruent singletons $(p>$ .20 for both contrasts). This ANOVA also revealed a significant main effect of target type $\left[F(1,16)=18.72, M S_{\mathrm{e}}=\right.$ $111,788.52, p<.01]$, reflecting the fact that RTs were shorter when the target was short $(M=894 \mathrm{msec})$ than when it was long $(M=1,116 \mathrm{msec})$. This main effect may reflect the fact that participants are able to start responding earlier to short targets than to long targets, because short targets offset earlier than long targets. However, to anticipate, a similar main effect is seen in the error rates, so that participants also make more errors on long-target trials than on short-target trials. It therefore seems likely that long targets are simply harder to detect than short targets and that this (perhaps in combination with timing effects) is behind the main effect seen here. There was no interaction between target type and singleton condition/congruency $[F(4,64)=$ $\left.1.63, M S_{\mathrm{e}}=9,794.73, p=.18\right]$.

A similar ANOVA on the error data from the duration singleton blocks revealed a significant effect of singleton condition/congruency $\left[F(4,64)=9.73, M S_{\mathrm{e}}=0.008, p<\right.$ $.01]$, as in Experiment 1. $F$ contrasts showed a significant facilitation effect (singleton-absent vs. singleton target trials) for congruent singletons $\left[F(1,16)=4.62, M S_{\mathrm{e}}=\right.$ $0.009, p<.05]$, but not for incongruent singletons $(F<1)$. Note, however, that the numerical trends for incongruent singletons were in the direction of a facilitation effect (see Table 1). There were also significant interference effects (singleton-absent vs. singleton distractor trials) both for the congruent singletons $\left[F(1,16)=6.30, M S_{\mathrm{e}}=0.010\right.$, $p<.05]$ and for the incongruent singletons $[F(1,16)=$ $21.50, M S_{\mathrm{e}}=0.011, p<.01$; see Table 1]. As with the analysis of the RT data, there was also a significant main effect of target type $\left[F(1,16)=11.45, M S_{\mathrm{e}}=0.007, p<\right.$ $.05]$, so that error rates were higher for long targets $(M=$ $13 \%)$ than for short targets $(M=9 \%)$. This supports the RT analysis in suggesting that the participants may have found the long targets harder to detect than the short targets. There was also a significant target type $\times$ singleton condition/congruency interaction $\left[F(4,64)=2.71, M S_{\mathrm{e}}=\right.$ $0.005, p<.05]$. Repeated $F$ contrasts showed that this interaction was driven by the interference effects elicited by incongruent singletons $\left[F(1,16)=6.715, M S_{\mathrm{e}}=0.009\right.$, $p<.05]$, so that the interference effect was stronger when the target was long $(M$ effect $=12 \%)$ than when it was short $(M$ effect $=4 \%)$. Note that the patterns of results were similar for interference effects of congruent singletons, with interference effects being stronger when the target was long $(M$ effect $=6 \%)$ than when it was short $(M$ effect $=2 \%$ ). However, this interaction did not reach significance, and neither did the interactions involving facilitation effects ( $p>.20$ for all comparisons). The finding that interference effects in the error data are stronger on long-target trials than on short-target trials is likely to relate to the fact that performance (as measured both by RTs and by error rates) is worse on long-target trials than on short-target trials, suggesting that long targets are harder to detect than short targets. Participants therefore appear to be more open to attentional capture on trials in which the target is harder to detect. It may be the case that under conditions of uncertainty, participants are likely to search for additional information to help them in their task.

Overall, the present analyses replicated those reported for Experiment 1 in demonstrating significant facilitation and interference effects associated with auditory duration singletons presented during a visual duration task. The present experiment extended these findings to show that interference and facilitation effects occur regardless of target-singleton congruency. This is an important finding, since it rules out explanations in terms of response-related processes, as will be considered further in the Discussion section.

Frequency singletons. As was expected, preliminary analysis showed no evidence for any effects of subjective congruency between frequency singletons and duration targets. The effects of frequency singletons will thus be assessed only in terms of singleton condition, and not in terms of target-singleton congruency. Preliminary analysis also indicated that the factor of singleton type (high vs. low frequency) did not interact with the factor of theoretical interest (singleton condition), and the data thus will be pooled across singleton type. Figure $3 \mathrm{~B}$ presents the mean RTs and error data for the frequency singleton blocks as a function of singleton condition.

A two-way within-participants ANOVA on the RT data from the frequency singleton blocks, with the factors of singleton condition and target type (long vs. short), revealed no significant effect of singleton condition $(F<1)$, indicating that frequency singletons did not affect RTs during the visual duration search task. There was a main effect of target type $\left[F(1,16)=19.58, M S_{\mathrm{e}}=122,440.06\right.$, $p<.01]$, indicating that RTs were shorter when the target was short $(M=861 \mathrm{msec})$ than when it was long $(M=$ $1,168 \mathrm{msec})$, as was also found in the duration singletons analysis. The two factors did not interact $(F<1)$.

By contrast to the RT analysis, a similar ANOVA performed on the error data revealed a significant main effect 
of singleton condition $\left[F(2,32)=3.72, M S_{\mathrm{e}}=0.003, p<\right.$ $.05] . F$ contrasts indicated that this main effect was driven by a trend for a facilitation effect (singleton absent vs. singleton target) that approached significance $[F(1,16)=$ $\left.3.42, M S_{\mathrm{e}}=0.005, p=.083\right]$. There was no significant interference effect (singleton absent vs. singleton distractor; $F<1$ ). The ANOVA showed no main effect of target type and no interaction between singleton condition and target type ( $F<1$ for both comparisons).

Overall, despite a trend for a facilitation effect in the error rates, frequency singletons appeared to produce fewer effects than did duration singletons. This possible difference will be investigated in more detail below.

Comparison between singleton conditions. An additional two-way within-participants ANOVA was run on the RT data to compare singleton effects between the duration singleton and the frequency singleton conditions. This ANOVA used the factors of singleton type (duration vs. frequency singleton) and singleton condition and showed a significant interaction between the two factors $\left[F(2,32)=5.88, M S_{\mathrm{e}}=2,454.96, p<.01\right] . F$ contrasts indicated that the singleton facilitation effect in the duration singleton condition was significantly larger than the corresponding effect in the frequency singleton condition $\left[F(1,16)=4.61, M S_{\mathrm{e}}=5,189.07, p<.05\right.$; see Figure 3]. There was no difference between the interference effects due to different types of singleton $(F<1)$, neither of which had been significant in the previous analyses. There was no overall effect of singleton type $(F<1)$, indicating that performance was comparable in the two conditions (this is perhaps unsurprising, given that the task was identical in both conditions).

A similar ANOVA was run on the error data. This also revealed a significant interaction between singleton type and singleton condition $\left[F(2,32)=5.76, M S_{\mathrm{e}}=15.97\right.$, $p<.01]$, indicating that the singleton interference effect observed in the duration singleton analysis was reduced significantly in the frequency singleton condition $\left[F(1,16)=12.87, M S_{\mathrm{e}}=22.66, p<.01\right.$; see Figure 3]. There was no difference in the facilitation effects $(F<1)$, neither of which had been significant in the previous analysis. Finally, as with the RT data, there was no overall effect of singleton type $(F<1)$, indicating that task performance was comparable for both types of singletons.

\section{Discussion}

The results of Experiment 2 replicated the significant interference and facilitation effects observed in Experiment 1 due to auditory duration singletons presented during a visual duration search task. The results also showed that these effects occur regardless of target-singleton congruency (i.e., auditory duration singletons cause interference or facilitation depending on their position relative to the target in the stream, and not on whether they are congruent or incongruent with the target in terms of their duration). This is an important finding, since it suggests that the effects cannot be explained in terms of responselevel effects, such as semantic confusion between response labels. For example, it is possible that when participants hear a short auditory singleton, they might simply be more likely to make a short response than a long response, regardless of the visual task. This would not constitute attentional capture, since it would simply reflect semantic confusion of response labels between the two sensory modalities. However, explanations along these lines would predict facilitation only when the target and the singleton were congruent and interference only when the two were incongruent. By contrast, the present experiment demonstrates both facilitation and interference effects for congruent and incongruent singletons. This casts any such response-level explanation of our results into doubt and, instead, suggests that any type of auditory singleton may draw attention to the point in the sequence at which it appears, affecting visual performance accordingly (leading to facilitation when it coincides with the target and interference when it coincides with a distractor).

The results of Experiment 2 also demonstrate that attentional capture effects are significantly reduced if singletons are presented on a stimulus dimension (frequency) with no relevance to the visual task (which was based on duration). It seems likely that frequency singletons failed to capture attention because the participants were "set" for duration and not for frequency, given that the visual task was one of duration search (e.g., Folk, Remington, \& Johnston, 1992). However, it is also possible that these frequency singletons were simply less salient than the duration singletons and, hence, may have failed to capture attention for this reason alone. This possibility was addressed in Experiment 3.

\section{EXPERIMENT 3}

In Experiment 3, we used duration singletons throughout the experiment (so that the physical salience of the singleton remained constant) and varied the visual task. In half of the blocks, the visual task was based on duration, so that the targets and the singletons were defined on the same dimension. In the other half of the blocks, the visual task was based on size, so that the targets and the singletons were defined on different dimensions. If the attentional capture demonstrated in our first two experiments was contingent on participants' being "set" for duration information, it should be eliminated in blocks in which the target is defined by size (since the participants should no longer be set for duration). If, however, the attentional capture effects were related solely to stimulus salience, the auditory duration singletons should capture attention throughout the experiment, regardless of the demands of the visual task.

\section{Method}

Participants. Sixteen new participants took part in this experiment, of which 7 were male and 15 were right-handed.

Stimuli and Procedure. The stimuli and procedure were similar to those used in Experiment 1, with the following exceptions. The sequences now consisted of five audiovisual stimuli. Visual targets were restricted to appearing in Serial Positions 2, 3, and 4. This change was introduced so that targets in every position could be either preceded or followed by a singleton stimulus to allow for an analysis of the effects of singleton position (before vs. after the target). Auditory singletons were defined by duration (as in Experi- 
ment 1) throughout the experiment. These singletons appeared at the same serial position as the visual target on $25 \%$ of the trials. They appeared directly before the target in the stream on a further $25 \%$ of the trials and directly after the target on another $25 \%$ of the trials. Singletons were absent on the remaining $25 \%$ of the trials. The participants carried out either the visual duration search task (as in Experiments 1 and 2) or a visual size search task, in different blocks. On size task blocks, the large stimuli subtended a visual angle of $1.6^{\circ}$ vertically and $1.8^{\circ}$ horizontally, and the small stimuli subtended a visual angle of $1.1^{\circ}$ vertically and $1.2^{\circ}$ horizontally, from a viewing distance of $60 \mathrm{~cm}$. As in the previous experiments, standard size stimuli subtended a visual angle of $1.4^{\circ}$ horizontally and $1.3^{\circ}$ vertically. Two short practice blocks (one for the duration task and one for the size task), each containing 15 trials, preceded four experimental blocks (two of the duration task and two of the size task), each containing 96 trials.

\section{Results}

Duration task. As a consequence of the modified design of the present experiment, singleton effects could now be assessed in terms of whether the singleton occurred before or after the target, as well as in terms of target-singleton congruency and singleton condition. Table $2 \mathrm{~A}$ presents mean RTs and error rates for duration singleton blocks as a function of singleton position/congruency (singleton absent vs. singleton target [congruent] vs. singleton target [incongruent] vs. singleton distractor [congruent, before target] vs. singleton distractor [incongruent, after target] vs. singleton distractor [congruent, before target] vs. singleton distractor [incongruent, after target]). By way of summary, Figure 4 presents mean RTs and error rates for the duration task (panel A) and the size task (panel B) as a function of singleton condition (singleton absent, singleton target, or singleton distractor).

As in the previous experiments reported here, a twoway within-participants ANOVA on the RT data from duration task blocks, with the factors of singleton position/ congruency (as described above) and target type (long vs. short), revealed a significant main effect of singleton position/congruency $\left[F(2.7,40.5)=12.49, M S_{\mathrm{e}}=\right.$ $104,830.12, p<.01]$. As in Experiment 2, $F$ contrasts revealed a significant facilitation effect (singleton absent vs. singleton target) due both to congruent singletons $\left[F(1,15)=19.61, M S_{\mathrm{e}}=65,529.71, p<.01\right]$ and to incongruent singletons $\left[F(1,15)=16.01, M S_{\mathrm{e}}=61,741.58\right.$,

Table 2A

Averages of Participants' Mean Response Times (RTs, in Milliseconds, With Standard Errors) and Mean Error Rates (in Percentages) for Duration Task Blocks in Experiment 3 As a Function of Singleton Condition

\begin{tabular}{cccc}
\hline Condition & RT & $S E$ & \%Error \\
\hline Singleton absent & 1,058 & 72 & 13 \\
Singleton target & & & 5 \\
Congruent & 858 & 45 & 10 \\
Incongruent & 882 & 47 & \\
Singleton distractor & & & \\
Congruent & 1,129 & 90 & 21 \\
Before & 997 & 57 & 10 \\
After & & & \\
Incongruent & 1,234 & 83 & 33 \\
Before & 951 & 48 & 15 \\
After & & & \\
\hline
\end{tabular}

$p<.01$; see Table 2A]. Incongruent singletons appearing before the target caused significant interference (singleton absent vs. singleton distractor) $\left[F(1,15)=12.05, M S_{\mathrm{e}}=\right.$ $84,150.55, p<.01]$, whereas congruent singletons appearing before the target did not $\left[F(1,15)=1.97, M S_{\mathrm{e}}=\right.$ $82,710.46, p=.18]$. Note, however, that the numerical trend in the data attributable to congruent singletons appearing before the target is toward interference. Singletons appearing after the target showed no significant interference effects $(p>.15)$, and in fact, incongruent singletons in this position showed a significant facilitatory effect $\left[F(1,15)=5.71, M S_{\mathrm{e}}=64,219.86, p<.05\right.$; see Table 2A]. This ANOVA also revealed a trend for a main effect of target type $\left[F(1,15)=3.46, M S_{\mathrm{e}}=358,065.09\right.$, $p=.082]$, suggesting that RTs were shorter when the target was short $(M=941 \mathrm{msec})$ than when it was long $(M=1,090 \mathrm{msec})$, as in Experiment 2. There was a significant interaction between target type and singleton position/congruency $\left[F(6,90)=4.02, M S_{\mathrm{e}}=43,144.26\right.$, $p<.01]$. $F$ contrasts indicated that this interaction was driven by the interference effect elicited by incongruent singletons appearing before the target $[F(1,15)=7.73$, $\left.M S_{\mathrm{e}}=112,137.18, p<.05\right]$, so that the effect was stronger for long targets $(M$ effect $=343 \mathrm{msec})$ than for short targets $(M$ effect $=14 \mathrm{msec})$. As in Experiment 2, the pattern of results was similar on singleton-congruent trials, with numerically larger interference effects for long targets $(M$ effect $=136 \mathrm{msec})$ than for short targets $(M$ effect $=7 \mathrm{msec})$, although this interaction did not reach significance $(p>.20)$. As was mentioned with reference to Experiment 2, it seems likely that the participants were simply more open to attentional capture on trials on which they found the task harder (i.e., long-target trials) than on trials on which they found the task easier (i.e., short-target trials). No other interactions reached significance in the $F$ contrast analysis ( $p>.15$ for all comparisons).

A similar ANOVA on the error data from the duration task blocks revealed a significant effect of singleton position/congruency $\left[F(6,90)=22.53, M S_{\mathrm{e}}=0.012, p<\right.$ $.01]$. $F$ contrasts highlighted a significant facilitation effect (singleton-absent vs. singleton target trials) for congruent singletons $\left[F(1,15)=13.34, M S_{\mathrm{e}}=0.014, p<\right.$ $.01]$, but not for incongruent singletons $(F<1)$, although note that the numerical trends in this case are in the direction of a facilitation effect (see Table 2A). There were also significant interference effects (singleton-absent vs. singleton distractor trials) for singletons appearing before the target, no matter whether they were congruent $[F(1,15)=$ $\left.15.87, M S_{\mathrm{e}}=0.013, p<.01\right]$ or incongruent $[F(1,15)=$ $42.06, M S_{\mathrm{e}}=0.030, p<.01$; see Table $\left.2 \mathrm{~A}\right]$. By contrast, singletons appearing after the target did not produce significant effects ( $p>.09$ for both contrasts). As with the analysis of the RT data, there was a significant main effect of target type $\left[F(1,15)=31.77, M S_{\mathrm{e}}=0.017, p<\right.$ $.01]$, so that performance was worse for long targets $(M=$ $17 \%)$ than for short targets $(M=9 \%)$. In addition, as in the RT analysis, there was an interaction between target type and singleton position/congruency $[F(2.9,43.9)=$ $\left.4.89, M S_{\mathrm{e}}=0.030, p<.01\right]$. This interaction appeared to be driven by the interference effects of incongruent 
A Duration Discrimination

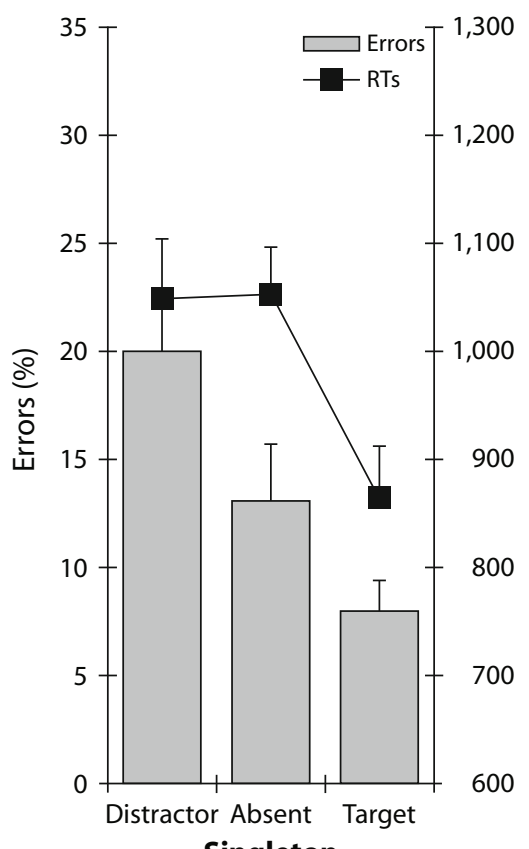

B Size Discrimination

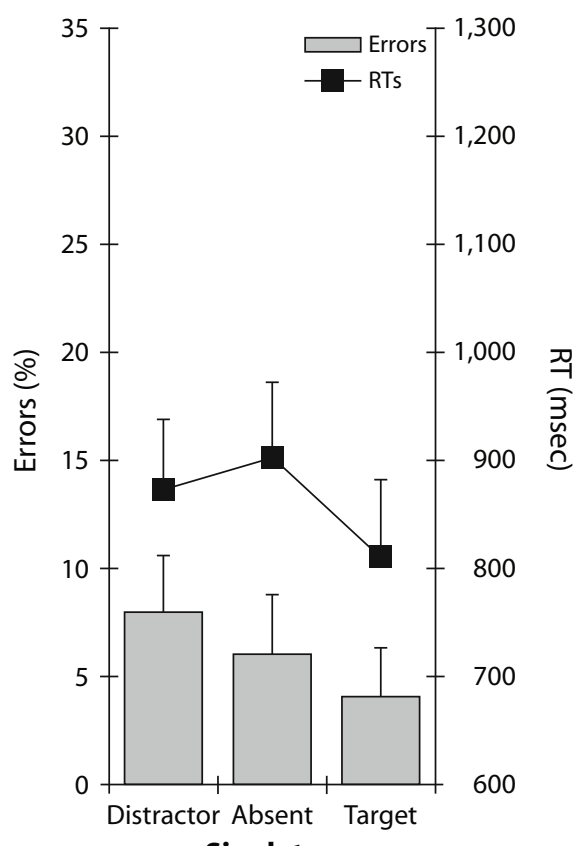

Singleton

Figure 4. Mean response times (RTs; shown in line graphs) and error rates (shown in bar graphs) from Experiment 3 as a function of singleton condition (singleton distractor, singleton absent, or singleton target) in the duration task (A) and the size task (B). Error bars represent the standard errors of the means.

singletons appearing before the target $[F(1,15)=10.17$, $\left.M S_{\mathrm{e}}=0.037, p<.01\right]$, so that effects were stronger for long targets $(M$ effect $=30 \%)$ than for short targets $(M$ effect $=9 \%$ ). Note, however, that congruent singletons showed numerical trends in the same direction as that for incongruent singletons, with larger effects for long targets $(M$ effect $=9 \%)$ than for short targets $(M$ effect $=$ $7 \%$ ), although this interaction did not reach significance and neither did any other of the comparisons $(p>.15$ for all).

Overall, the duration task data from the present experiment replicated the results of Experiments 1 and 2 in confirming the fact that auditory duration singletons capture attention during a visual duration search task. These findings also confirm the results of Experiment 2 in showing that attentional capture effects occur regardless of target-singleton congruency, suggesting that the effects are due to attentional capture by the singletons, rather than to response-related processes. Finally, the present results extended our previous experiments by showing that the singleton interference arises mainly due to singletons appearing before, rather than after, the target. This finding will be considered further in the Discussion section.

Size task. As was expected, preliminary analysis showed no evidence for effects of subjective congruency between duration singletons and size targets. The effects of duration singletons in the present task are therefore assessed in terms of singleton condition (including before/after target) and target type only, and not in terms of target-singleton congruency. Table $2 \mathrm{~B}$ presents mean
RTs and error rates for size task blocks as a function of singleton position (singleton absent vs. singleton target vs. singleton distractor before target vs. singleton distractor after target).

A two-way within-participants ANOVA was conducted on the RT data from the size task blocks with the factors of singleton position (singleton absent vs. singleton target vs. singleton distractor before target vs. singleton distractor after target) and target size (large vs. small). This analysis showed a significant effect of singleton position $[F(1.9$, $\left.27.9)=6.21, M S_{\mathrm{e}}=13,543.56, p<.01\right] . F$ contrasts revealed a significant facilitation effect [singleton absent vs. singleton target trials; $F(1,15)=10.50, M S_{\mathrm{e}}=$ $27,159.76, p<.01$ ] but no interference effect (singletonabsent vs. singleton distractor trials) of singletons appearing either before or after the target $(p>.10$ for both comparisons; see Table 2B). There was no main effect of

Table 2B

Averages of Participants' Mean Response Times (RTs, in Milliseconds, With Standard Errors) and Mean Error Rates (in Percentages) for Size Task Blocks in Experiment 3 As a Function of Singleton Condition

\begin{tabular}{lllc}
\hline \multicolumn{1}{c}{ Condition } & RT & $S E$ & \%Error \\
\hline Singleton absent & 900 & 70 & 6 \\
Singleton target & 806 & 69 & 5 \\
Singleton distractor & & & \\
Before & 875 & 68 & 9 \\
After & 873 & 63 & 8 \\
\hline
\end{tabular}


target size, and the two factors did not interact $(F<1$ for both comparisons).

A similar ANOVA on the error data from the size task blocks found a significant effect of singleton position $\left[F(3,45)=3.57, M S_{\mathrm{e}}=0.003, p<.05\right] . F$ contrasts revealed that this interaction was driven by a trend for a facilitation effect (singleton absent vs. singleton target trials) that approached significance $\left[F(1,15)=3.47, M S_{\mathrm{e}}=\right.$ $0.003, p=.082]$, as well as by a trend for an interference effect (singleton-absent vs. singleton distractor trials) due to singletons appearing before the target, which also approached significance $\left[F(1,15)=3.33, M S_{\mathrm{e}}=0.006, p=\right.$ .088 ; see Table 2B]. Singletons appearing after the target did not show interference effects $(F<1)$. There was no main effect of target size, and the two factors did not interact ( $p>.10$ for both comparisons).

Between-task comparison. A two-way withinparticipants ANOVA was performed on the RT data to compare singleton effects between the duration and the size tasks. This ANOVA used the factors of task (duration vs. size) and singleton position (singleton absent, singleton target, singleton distractor before target, or singleton distractor after target). This analysis revealed a significant interaction between the two factors $[F(2.1,30.9)=$ 6.95, $\left.M S_{\mathrm{e}}=13,979.81, p<.01\right] . F$ contrasts suggested that this interaction was due, in part, to a lack of interference effects, due to singletons occurring before the target in the size task ( $M$ effect $=-23 \mathrm{msec}$ ), as compared with a strong interference effect due to these singletons in the duration task $(M$ effect $=93 \mathrm{msec})[F(1,15)=8.41$, $\left.M S_{\mathrm{e}}=12,726.91, p<.05\right]$. There was a suggestion that the overall interaction was also driven by a reduced facilitation effect (singleton target vs. singleton absent) in the size task ( $M$ effect $=92 \mathrm{msec})$, as compared with the duration task $(M$ effect $=188 \mathrm{msec})$, although this interaction did not quite reach significance $\left[F(1,15)=3.96, M S_{\mathrm{e}}=\right.$ $18,606.26, p=.065]$. There was also a significant main effect of task $\left[F(1,15)=4.52, M S_{\mathrm{e}}=145,117.51, p=.05\right]$, so that RTs were shorter in the size task $(M=865 \mathrm{msec})$ than in the duration task $(M=1,008 \mathrm{msec})$. One might have expected RTs to be longer in the duration task than in the size task, because, whereas size information is present from the onset of the stimulus, duration information is not immediately available (see note 2). However, to anticipate, since a similar main effect is also seen in the error analysis (with higher error rates in the duration task than in the size task), it seems likely that the duration task was also genuinely more difficult than the size task.

A similar ANOVA performed on the error data revealed a significant interaction between task and singleton position $\left[F(3,45)=16.55, M S_{\mathrm{e}}=21.84, p<.01\right] . F$ contrasts indicated that this interaction was driven by a reduced interference effect of singletons occurring before the target in the size task, as compared with the duration task $\left[F(1,15)=29.90, M S_{\mathrm{e}}=46.19, p<.01\right.$; see Tables 2A and $2 \mathrm{~B}]$. There was no difference in the facilitation effects or in the interference effects of singletons appearing after the target ( $p>.15$ for both comparisons). Finally, there was a significant overall effect of task $[F(3,45)=36.48$, $\left.M S_{\mathrm{e}}=21.77, p<.01\right]$, indicating that performance was better in the size task $(M=7 \%)$ than in the duration task $(M=15 \%)$.

\section{Discussion}

Experiment 3 replicated the findings of both of the previous experiments in demonstrating interference and facilitation effects associated with auditory duration singletons in a visual duration task. As in Experiment 2, these effects were shown to be largely independent of targetsingleton congruency. However, the present experiment shows that interference effects are caused only by those singletons that appear before the target, and not by those appearing after the target in the stream. We note, however, that because the participants were able to respond as soon as the target had been presented, the effects of singletons appearing after the target may have been underestimated, since the participants may have responded (or initiated a response) before the singleton was presented.

The present experiment also suggests that the effects of auditory duration singletons can be reduced simply by changing the demands of the visual task (from duration discrimination to size discrimination). This suggests, in line with the results of Experiment 2, that singletons falling outside the participant's task set are less likely to capture attention than are those falling within the set. However, the present findings extend those of Experiment 2 to suggest that the observed reduction in singleton effect is unlikely to be due to reduced singleton salience, since the same singletons were used throughout Experiment 3.

We note, however, that the duration singletons used here did produce some significant effects on the visual size task, causing facilitation when they coincided with the target (this effect was significant in the RT data and showed a trend in the error data). Recall, in addition, that there was some suggestion in Experiment 2 of facilitation effects due to frequency singletons coinciding with duration targets (as indicated by a trend in the error data). Taken together, these results might suggest that capture is not entirely contingent on the singleton's being defined on the same dimension as the target; it may simply be the case that capture effects can be made stronger (leading to interference, as well as to facilitation) under such conditions. However, conclusions about the results of Experiment 3 are restricted by the fact that performance in the size task was significantly better than performance in the duration task. Thus, it could be argued that the size task was simply so easy that the participants were performing close to ceiling throughout, leaving little room for observation of singleton effects. Experiment 4 was designed to test this possibility.

\section{EXPERIMENT 4}

Experiment 4 used the same tasks and singletons as those in Experiment 3, but the stimuli were modified with the aim of making the size task easier and the duration task more difficult. The long, medium, and short visual stimuli used for the duration task were made easier to discriminate (lasting 600, 300, and $100 \mathrm{msec}$, respectively, as compared with 400,150 , and $50 \mathrm{msec}$ in the previous experiments). 
And the large, medium, and small visual stimuli used for the size task were made harder to discriminate (subtending $1.6^{\circ}, 1.5^{\circ}$, and $1.4^{\circ}$ horizontally, respectively, as compared with $1.8^{\circ}, 1.4^{\circ}$, and $1.2^{\circ}$ in our previous experiments). Note that in order to accommodate the longer visual durations, stimulus presentation was slowed down throughout the experiment. The durations of the long, medium, and short auditory stimuli were, therefore, increased (lasting 600, 400, and $200 \mathrm{msec}$, respectively, as compared with 400, 150, and $50 \mathrm{msec}$ in the previous experiments). This change to the design also had the benefit of ruling out the possibility that the auditory stimuli in the previous experiments captured attention through being unique in timbre, as well as in duration. Very short stimuli (such as the 50-msec short auditory singletons used in the previous experiments) can be perceived as being different in timbre from longer stimuli (e.g., one of our participants reported hearing the short stimuli as "clicks"), meaning that the short stimuli might have been perceived as unique in both duration and timbre. However, because the short stimuli used in the present experiment were $200 \mathrm{msec}$ in duration, they should not have been perceived as unique in timbre, and any capture effects in this experiment would be due to the auditory stimuli's being unique solely in duration.

\section{Method}

Participants. Sixteen new participants took part in this experiment, of which 6 were male and all were right-handed.

Stimuli and Procedure. The stimuli and procedure were similar to those used in Experiment 3, with the following exceptions. The item-to-item SOA (including stimulus presentation and a randomly picked jitter interval) was increased, relative to previous experiments, lasting between 650 and $800 \mathrm{msec}$. On duration task blocks, visual targets were defined by duration. Short targets had a duration of $100 \mathrm{msec}$, long targets a duration of $600 \mathrm{msec}$, and nontargets an intermediate duration of $300 \mathrm{msec}$. These durations were chosen with the aim of reducing the difficulty of the duration task in the present experiment, by comparison with the previous experiments. On size task blocks, large stimuli subtended a visual angle of $1.4^{\circ}$ vertically and $1.6^{\circ}$ horizontally, small stimuli subtended a visual angle of $1.3^{\circ}$ vertically and $1.4^{\circ}$ horizontally, and standard size stimuli subtended a visual angle of $1.4^{\circ}$ vertically and $1.5^{\circ}$ horizontally, all from a viewing distance of $60 \mathrm{~cm}$. These sizes were chosen with the aim of increasing difficulty in the size task in the present experiment, by comparison with Experiment 3. The auditory stimuli were also changed in the present experiment, with long singletons having a duration of $600 \mathrm{msec}$, short singletons having a duration of $200 \mathrm{msec}$, and nonsingleton distractors having a duration of $400 \mathrm{msec}$.

\section{Results}

Duration task. Table 3A presents mean RTs and error rates for duration singleton blocks as a function of singleton position/congruency (singleton absent vs. singleton target [congruent] vs. singleton target [incongruent] vs. singleton distractor [congruent, before target] vs. singleton distractor [incongruent, after target] vs. singleton distractor [congruent, before target] vs. singleton distractor [incongruent, after target]). By way of summary, Figure 5 presents mean RT and error data for the duration task (panel A) and the size task (panel B) as a function of singleton condition (singleton absent vs. singleton target vs. singleton distractor).
Table 3A

Averages of Participants' Mean Response Times (RTs, in Milliseconds, With Standard Errors) and Mean Error Rates (in Percentages) for Duration Task Blocks in Experiment 4 As a Function of Singleton Condition

\begin{tabular}{cccc}
\hline Condition & RT & $S E$ & \%Error \\
\hline Singleton absent & 1,103 & 57 & 10 \\
Singleton target & & & \\
Congruent & 940 & 41 & 8 \\
$\quad$ Incongruent & 972 & 47 & 9 \\
Singleton distractor & & & \\
$\quad$ Congruent & 1,080 & 56 & 20 \\
Before & 1,102 & 63 & 12 \\
After & & & \\
Incongruent & 1,170 & 39 & 24 \\
Before & 1,066 & 56 & 11 \\
After & & & \\
\hline
\end{tabular}

As in Experiment 3, a two-way within-participants ANOVA on the RT data from the duration task blocks, with the factors of singleton position/congruency (as described above) and target type (long vs. short), revealed a significant main effect of singleton position/congruency $\left[F(6,90)=7.81, M S_{\mathrm{e}}=26,182.50, p<.01\right]$. As in Experiment $3, F$ contrasts revealed a significant facilitation effect (singleton absent vs. singleton target) due both to congruent singletons $\left[F(1,15)=18.33, M S_{\mathrm{e}}=46,564.36\right.$, $p<.01]$ and to incongruent singletons $[F(1,15)=21.71$, $M S_{\mathrm{e}}=25,420.88, p<.01$; see Table 3A]. There were no significant interference effects (singleton absent vs. singleton distractor) in the RT data ( $p>.15$ for all comparisons). This ANOVA also revealed a main effect of target type $\left[F(1,15)=43.02, M S_{\mathrm{e}}=337,230.08, p<.01\right]$, indicating that RTs were shorter when the target was short $(M=807 \mathrm{msec})$ than when it was long $(M=1,316 \mathrm{msec})$, as has already been reported in Experiments 2 and 3 . There was a significant interaction between target type and singleton position/congruency $\left[F(6,90)=5.96, M S_{\mathrm{e}}=\right.$ 25,840.77, $p<.01]$. $F$ contrasts indicated that this interaction was driven by the facilitation effects: The facilitation effect of congruent singletons was stronger for long targets $(M$ effect $=283 \mathrm{msec})$ than for short targets $(M$ effect $=43 \mathrm{msec})\left[F(1,15)=36.97, M S_{\mathrm{e}}=12,551.19\right.$, $p<.01]$; similarly, the facilitation effect of incongruent singletons was stronger for long targets $(M$ effect $=$ $301 \mathrm{msec})$ than for short targets $(M$ effect $=-38 \mathrm{msec})$ $\left[F(1,15)=37.56, M S_{\mathrm{e}}=24,503.70, p<.01\right]$. Note that although the effect of incongruent singletons coinciding with short targets appears to indicate a 38-msec interference effect (in contrast to the expected facilitation effect), this effect was, in fact, not significant $(t=1)$. Once again, it seems that there was more scope for attentional capture effects on trials on which the participants' performance was worse (i.e., long-target trials) than on trials on which performance was better (i.e., short-target trials). No other interactions reached significance in the $F$ contrast analysis ( $p>.15$ for all comparisons).

A similar ANOVA on the error data from the duration task blocks revealed a significant effect of singleton position/congruency $\left[F(3.9,58.3)=11.24, M S_{\mathrm{e}}=0.017\right.$, $p<.01] . F$ contrasts highlighted significant interference 

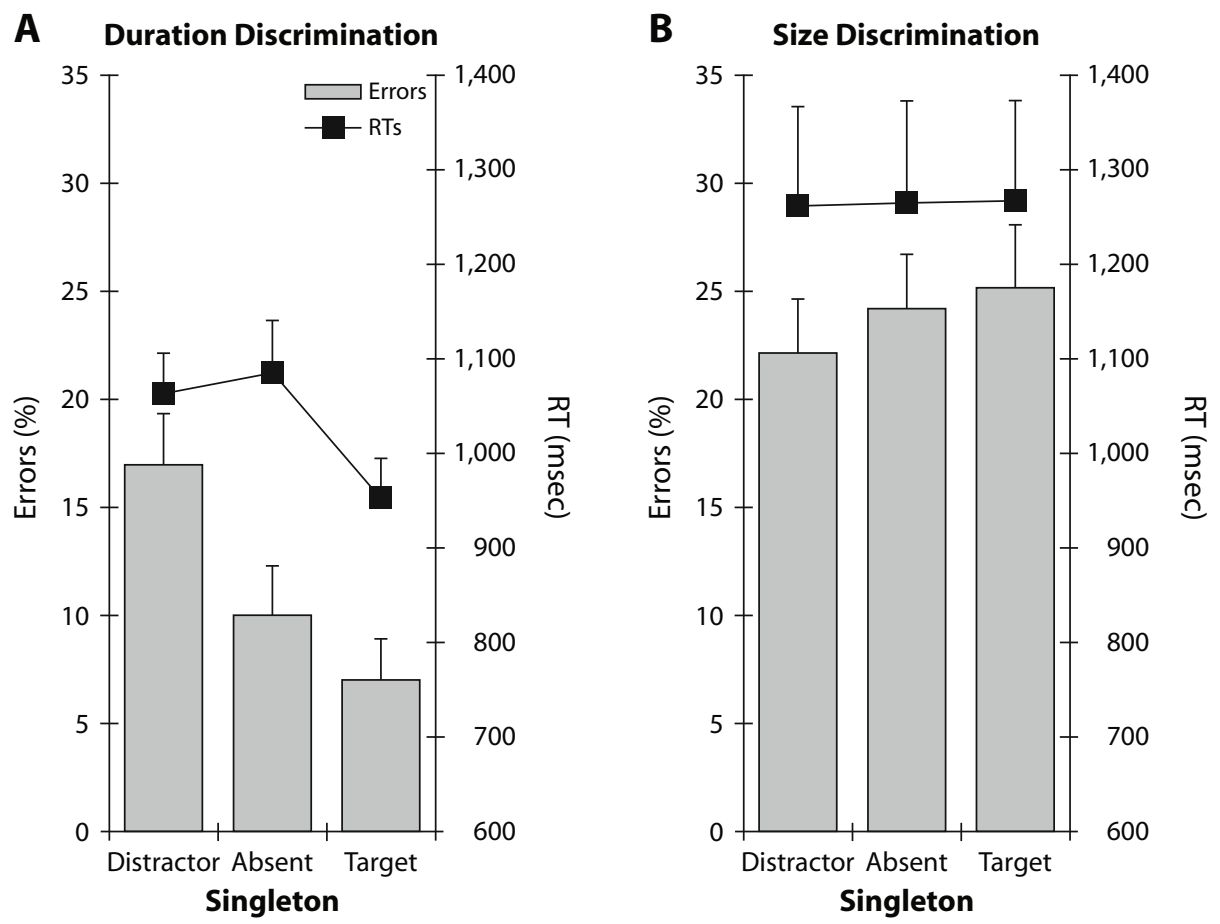

Figure 5. Mean response times (RTs; shown in line graphs) and error rates (shown in bar graphs) from Experiment 4 as a function of singleton condition (singleton distractor, singleton absent, or singleton target) in the duration task (A) and the size task (B). Error bars represent the standard errors of the means.

effects (singleton-absent vs. singleton distractor trials) for singletons appearing before the target, no matter whether they were congruent $\left[F(1,15)=10.05, M S_{\mathrm{e}}=0.034, p<\right.$ $.01]$ or incongruent $\left[F(1,15)=42.24, M S_{\mathrm{e}}=0.016, p<\right.$ .01 ; see Table $3 \mathrm{~A}]$. No other contrasts were significant ( $F<1$ for all comparisons). As with the RT analysis, there was a significant main effect of target type $[F(1,15)=$ $\left.17.14, M S_{\mathrm{e}}=0.039, p<.01\right]$, so that performance was worse for long targets $(M=19 \%)$ than for short targets $(M=8 \%)$. As in the RT analysis, there was also an interaction between target type and singleton position/congruency $\left[F(3.7,55.3)=8.65, M S_{\mathrm{e}}=0.016, p<.01\right]$. This interaction appears to have been driven by two main interactions in the $F$ contrast analysis. First, interference effects of incongruent singletons appearing before the target were stronger for long targets $(M$ effect $=24 \%)$ than for short targets $(M$ effect $=5 \%)\left[F(1,15)=16.76, M S_{\mathrm{e}}=0.019\right.$, $p<.01]$. Note that congruent singletons showed numerical trends in the same direction as incongruent singletons, with larger effects for long targets $(M$ effect $=13 \%)$ than for short targets $(M$ effect $=8 \%)$. However, this interaction did not reach significance $\left[F(1,15)=3.30, M S_{\mathrm{e}}=\right.$ $0.007, p=.09]$. Second, although the main effects of facilitation due to congruent and incongruent singletons coinciding with the target did not reach significance $(F<1$ for both comparisons), these effects did interact with target type. Congruent singletons had a facilitatory effect when the target was long $(M$ facilitation effect $=7 \%$ ), which reversed to an interference effect when the target was short $(M$ interference effect $=3 \%)\left[F(1,15)=28.77, M S_{\mathrm{e}}=\right.$
$0.002, p<.01]$. Similarly, incongruent singletons showed a facilitatory effect when the target was long ( $M$ facilitation effect $=7 \%$ ), which reversed to an interference effect when the target was short $(M$ interference effect $=4 \%)$ $\left[F(1,15)=6.14, M S_{\mathrm{e}}=0.013, p<.05\right]$. Note, however, that although both the facilitation effects were significant $[t(15)=3.36, p<.01$, for congruent singletons; $t(15)=$ $2.30, p<.05$, for incongruent singletons], neither of the interference effects was significant ( $p>.10$ for both comparisons). Thus, as for the RT data, it seems to be the case that the participants were performing at near-ceiling level for short targets, which would have been likely to reduce the singleton effects on those trials.

Taken together, the duration task data replicated the results of Experiment 3 in confirming that auditory duration singletons capture attention during a visual duration search task, leading to facilitation (as measured by shorter RTs) when they coincided with targets and to interference (as measured by lower accuracy) when they coincided with distractors. As in the previous experiments, the effects occurred regardless of target-singleton congruency, suggesting that the effects were due to attentional, rather than to response-related, processes. As in Experiment 3, singleton interference was caused mainly by singletons appearing before, rather than after, the target. The replication of these findings within the present design, in which the shortest singleton lasted $200 \mathrm{msec}$, rules out the possibility that the shorter $(50-\mathrm{msec})$ singletons used in the previous experiments had their effects because they were perceived as unique in both duration and timbre. 
Size task. Table 3B presents mean RTs and error rates for size task blocks as a function of singleton position (singleton absent, singleton target, singleton distractor before target, or singleton distractor after target).

A two-way within-participants ANOVA was conducted on the RT data from the size task blocks, with the factors of singleton position and target size (large vs. small). In contrast to Experiment 3, there was no main effect of singleton position $(F<1)$. However, there was a significant effect of target size $\left[F(1,15)=21.39, M S_{\mathrm{e}}=\right.$ $330,915.74, p<.01]$, so that responses were slower for small targets $(M=1,507 \mathrm{msec})$ than for large targets $(M=1,037 \mathrm{msec})$. There was no interaction between the two factors $\left[F(3,45)=1.26, M S_{\mathrm{e}}=18,628.44, p=.30\right]$.

A similar ANOVA on the error data from the size task blocks found no main effects or interactions ( $p>.15$ for all comparisons).

Between-task comparison. A two-way withinparticipants ANOVA was performed on the RT data to compare singleton effects between the duration and size tasks, using the factors of task (duration vs. size) and singleton position (singleton absent vs. singleton target vs. singleton distractor before target vs. singleton distractor after target). This showed a significant interaction between the two factors $\left[F(3,45)=4.70, M S_{\mathrm{e}}=7,032.48, p<.01\right]$. $F$ contrasts suggested that this interaction was driven by a reduced facilitation effect (singleton target vs. singleton absent $)$ in the size task ( $M$ effect $=-1 \mathrm{msec})$, as compared with the duration task $(M$ effect $=132 \mathrm{msec})[F(1,15)=$ 9.12, $\left.M S_{\mathrm{e}}=15,073.79, p<.01\right]$. There was also a main effect of task $\left[F(1,15)=6.89, M S_{\mathrm{e}}=219,971.85, p<\right.$ $.05]$, so that RTs were shorter in the duration task $(M=$ $1,042 \mathrm{msec})$ than in the size task $(M=1,260 \mathrm{msec})$. Note that this effect is in the opposite direction from that in Experiment 3 , suggesting that the changes to the stimuli did, indeed, result in the size task's becoming more difficult than the duration task.

An ANOVA performed on the error data revealed a similar pattern of results. There was a significant interaction between task and singleton position $[F(3,45)=14.51$, $\left.M S_{\mathrm{e}}=0.003, p<.01\right] . F$ contrasts indicated that this interaction was driven by a reduced interference effect of singletons occurring before the target in the size task ( $M$ effect $=-2 \%)$ than in the duration task $(M$ effect $=12 \%)$ $\left[F(1,15)=23.17, M S_{\mathrm{e}}=0.007, p<.01\right.$; see Tables $3 \mathrm{~A}$ and $3 \mathrm{~B}]$. Lastly, in line with the RT data, there was a significant overall effect of task $\left[F(1,15)=13.01, M S_{\mathrm{e}}=\right.$ $0.029, p<.01]$, indicating that performance was better in

Table 3B

Averages of Participants' Mean Response Times (RTs, in Milliseconds, With Standard Errors) and Mean Error Rates (in Percentages) for Size Task Blocks in Experiment 4 As a Function of Singleton Condition

\begin{tabular}{lccc}
\hline \multicolumn{1}{c}{ Condition } & RT & $S E$ & \%Error \\
\hline Singleton absent & 1,271 & 105 & 24 \\
Singleton target & 1,270 & 111 & 25 \\
Singleton distractor & & & \\
$\quad$ Before & 1,269 & 106 & 24 \\
After & 1,278 & 107 & 22 \\
\hline
\end{tabular}

the duration task $(M=13 \%)$ than in the size task $(M=$ $24 \%$ ). Again, this suggests that the stimulus manipulations intended to increase the difficulty of the size task, relative to the duration task, had the desired effect.

\section{Discussion}

The results of Experiment 4 replicated the findings of Experiment 3 in demonstrating interference and facilitation effects associated with auditory duration singletons in a visual duration task. These effects were largely independent of target-singleton congruency, and interference effects were caused only by singletons appearing before the target, as was also found in Experiment 3. However, in contrast to Experiment 3, in which the duration task was more difficult than the size task, in the present experiment, the size task was actually more difficult than the duration task. Despite this change, auditory duration singletons in Experiment 4 had significantly reduced effects in the size task, as compared with the duration task, just as in Experiment 3 . Thus, the reduced effects of duration singletons in the size task, relative to the duration task, cannot be explained in terms of reduced task difficulty in the size task, as compared with the duration task. This strengthens the claim that singletons falling outside the participant's task set are less likely to capture attention than are those falling within the set. Indeed, duration singletons caused no significant effects on the size task in Experiment 4, in contrast to Experiment 3, in which duration singletons had small but significant capture effects on the size task.

\section{GENERAL DISCUSSION}

The present study provides the first demonstration of attentional capture by irrelevant auditory singletons in a sequential visual search task. Experiment 1 showed facilitation effects when singletons coincided with visual targets (so that attention was drawn to a relevant item in the sequence) and interference effects when singletons coincided with distractors (so that attention was drawn to an irrelevant item). These effects were replicated in Experiment 2 and, using a modified task, in Experiments 3 and 4. All four experiments thus converge in providing a robust demonstration of attentional capture by irrelevant auditory singletons presented during a sequential visual search task.

Experiment 1 failed to show attentional capture due to visual duration singletons presented during an auditory search task. It is possible that this failure was linked to the relative ease with which the participants could perform the auditory task (by comparison with the visual task). Alternatively (or perhaps additionally), the visual singletons used in Experiment 1 may not have been sufficiently salient to produce attentional capture. Although further research will be necessary in order to explain the lack of capture by visual singletons in this experiment, an investigation of these issues was beyond the scope of the present study.

Experiments 2, 3, and 4 demonstrated that the capture effects due to auditory duration singletons in Experiment 1 could not be explained in terms of response-level processes (such as semantic confusion between response la- 
bels), because they occurred regardless of target-singleton congruency. This finding is also important in ruling out explanations in terms of cross-modal perceptual illusions. There is evidence that when auditory and visual stimuli are presented simultaneously, aspects of one stimulus can alter participants' perception of related aspects of the other stimulus. For example, the presence of a task-irrelevant light has been shown to facilitate detection of a low-intensity auditory stimulus (e.g., Lovelace, Stein, \& Wallace, 2003; see also Odgaard, Arieh, \& Marks, 2003; Stein, London, Wilkinson, \& Price, 1996). Thus, it is possible that the presence of an auditory singleton may have affected perception of a visual stimulus presented at the same time in the stream, so that a visual stimulus of intermediate duration would appear longer if it were accompanied by a long auditory singleton and shorter if it were accompanied by a short auditory singleton (there is evidence that auditoryvisual duration conflicts of this type are usually resolved in favor of audition; see, e.g., Walker \& Scott, 1981). However, were the effects found here to be attributable to such perceptual illusions, the facilitation effects should have occurred only when the target and the singleton were congruent (when any cross-modal perceptual illusions would have made long targets appear longer and short targets appear shorter), and not when the singleton and the target were incongruent (when any perceptual illusions would have made long targets appear shorter and short targets appear longer). By contrast, however, facilitation effects occurred regardless of target-singleton congruency, casting doubt on this explanation and, instead, supporting an alternative account in terms of attentional capture.

The results of Experiments 3 and 4 suggested that interference effects were driven by singletons appearing before (rather than after) the target in the stream. We note that the effects of singletons appearing after the target are likely to have been underestimated in the present design, since the participants were able to respond as soon as the target had been presented (making it possible that they could have responded or initiated a response before presentation of a following singleton). Nevertheless, these findings are reminiscent of the pattern of results found in previous studies of visual attentional capture in sequential search tasks (e.g., Dalton \& Lavie, 2006; Folk et al., 2002), in which attentional capture effects have typically been found only for singleton items preceding the target in the stream, and not for singletons that follow the target. These findings also appear to resemble the $\mathrm{AB}$ effect, in which attentional allocation toward a particular item in an RSVP stream impedes the processing of subsequent items. However, stimuli that produce an $\mathrm{AB}$ do so because they are deliberately attended to, and the $\mathrm{AB}$ literature does not, therefore, speak directly to the issue of attentional capture by irrelevant singletons. In addition, the cross-modal $\mathrm{AB}$ designs often involve switching between a task that is performed on the target item and a different task that is performed on the following probe item. Apparent effects of cross-modal $\mathrm{AB}$ can, therefore, often be explained in terms of amodal task-switching deficits, rather than in terms of attentional allocation toward the target item (see Chun \& Potter, 2001; Soto-Faraco \& Spence, 2002). Since the singletons used in the present experiment were always irrelevant to the task and never required a response, they would not be expected to have caused any task-switching effects. Thus, the present results are among the first to demonstrate performance costs and benefits that are unequivocally linked to temporal attentional allocation to items presented in a different sensory modality than is the target item.

The finding of significant interference effects due to auditory singletons appearing before the visual target in the stream might, at first, appear to stand in contrast to the results of Vroomen and de Gelder (2000, Experiment 2). They found no effects of high-frequency singletons occurring directly before targets in a spatial discrimination task. However, in their experiment, whenever the singleton appeared, it always directly preceded the target. Thus, it was predictive of the target's position in the repeating sequence and was, therefore, less likely to cause interference than were the singletons used in the present experiments (which were completely unpredictive of the target's sequential position). In addition, the high-frequency singleton in Vroomen and de Gelder's study would have been likely to fall outside the attentional set engendered by the visual task (which involved spatial localization of a target pattern). Similarly, when singletons in the present experiments were defined on a task-irrelevant dimension, there was some evidence for facilitation effects when the singleton coincided with the target (which might be comparable to the facilitation effects observed in Vroomen and de Gelder, 2000, Experiment 1, in which the target and the singletons always coincided) but little suggestion of interference effects when the singletons appeared either before or after the target. Thus, we do not believe that our results contradict Vroomen and de Gelder's findings. Note, however, that our use of short stimulus sequences (containing four or five stimuli), along with relatively small frequency separations $(40 \mathrm{~Hz})$ between nontargets and singletons means that the singletons in the present experiments were unlikely to have been perceptually segregated from nontargets (see Bregman, 1990). Thus, in contrast to the findings of Vroomen and de Gelder's study, the present results are likely to involve attentional capture by singleton sounds that attract attention because they are unique, as compared with the other stimuli in the group, rather than because they are perceptually grouped separately from the other sounds.

The fact that visual discrimination performance can be facilitated by the presence of a simultaneous auditory singleton suggests that the singleton draws attention toward entire audiovisual events, rather than simply toward the auditory component of an event. This finding could fit with a recent theory of dynamic attending (e.g., Barnes \& Jones, 2000; Large \& Jones, 1999; see Jones, 2001, for a review), in which it is proposed that attentional energy can be targeted at particular points in time. The theory relates to situations in which attention is targeted according to rhythmic expectancies but also describes situations in which attention is captured by sounds occurring at unexpected onset times. The present experiments suggest that attentional capture by other types of unique item (e.g., 
those with unique duration) might also result in increased attentional energy to the event containing the singleton feature. This raises the interesting question of what might happen if the stimuli in our study were presented from different spatial locations. Would attention to a relevant point in time lead to facilitation of all events occurring at that time, regardless of their spatial location? Or would attentional facilitation be restricted to events occurring at the same spatial location as the singleton? These are certainly interesting areas for future research.

Experiments 2, 3, and 4 showed that capture effects were significantly reduced if singletons were presented on a stimulus dimension with no relevance to the visual task. This suggests that the attentional capture effects demonstrated here are, to some extent, contingent on participants' adopting an appropriate task set. This concurs with previous suggestions that attentional capture is not automatic but, instead, depends on the attentional control settings adopted by the observer (e.g., Folk et al., 1992; Folk \& Remington, 1998). However, the present study also suggests that such attentional settings can be made across sensory modalities, if the dimension used is meaningful in both modalities (as is the dimension of duration). As far as we are aware, this is the first demonstration of the influence of attentional control settings extending across different sensory modalities.

However, although attentional capture was clearly reduced in situations in which the target and the singleton were defined on different dimensions, it was not altogether eliminated. In Experiments 2 and 3, there were small but reliable effects of singletons defined on task-irrelevant dimensions. Thus, capture effects can occur even when targets and singletons are defined on different dimensions; they simply appear to be weaker under these circumstances. Note, however, that these weaker effects do not necessarily constitute involuntary attentional capture with no involvement of top-down control. It is possible that even when singletons are defined on a dimension different from that for the targets, they nevertheless fall within the participant's attentional set. For example, participants could adopt a singleton detection strategy in which they searched for any unique item, rather than focusing on the particular target feature (see Bacon \& Egeth, 1994). This would have meant that pitch singletons presented during a duration task (in Experiment 2) and duration singletons presented during a size task (in Experiment 3 ) fell within the participants' task set, simply by virtue of being singletons. The small yet significant capture effects due to these singletons could, therefore, still be contingent on the singletons' falling within the participants' set. This is an interesting possibility, not least because it would suggest that the singleton detection strategy could apply crossmodally, for both visual and auditory stimuli.

\section{AUTHOR NOTE}

This research was supported by an Economic and Social Research Council (U.K.) Postdoctoral Fellowship PTA-026-27-0550 to P.D. and a Junior Research Fellowship from St Anne's College, Oxford to P.D. We thank Mari Riess Jones, Lawrence Ward, and two anonymous reviewers for their very helpful comments on earlier drafts of this work. Correspondence concerning this article should be addressed to P. Dalton, De- partment of Psychology, Royal Holloway University of London, Egham, Surrey TW20 0EX, England (e-mail: polly.dalton@rhul.ac.uk).

\section{REFERENCES}

ARnell, K. M., \& Duncan, J. (2002). Separate and shared sources of dual-task cost in stimulus identification and response selection. $\mathrm{Cog}_{-}$ nitive Psychology, 44, 105-147.

ARNell, K. M., \& Jenkins, R. (2004). Revisiting within-modality and cross-modality attentional blinks: Effects of target-distractor similarity. Perception \& Psychophysics, 66, 1147-1161.

ArNell, K. M., \& Jolicceur, P. (1999). The attentional blink across stimulus modalities: Evidence for central processing limitations. Journal of Experimental Psychology: Human Perception \& Performance, 25, 630-648.

Arnell, K. M., \& Larson, J. M. (2002). Cross-modality attentional blinks without preparatory task-set switching. Psychonomic Bulletin \& Review, 9, 497-506.

Bacon, W. F., \& EgEth, H. E. (1994). Overriding stimulus-driven attentional capture. Perception \& Psychophysics, 55, 485-496.

BARNes, R., \& Jones, M. R. (2000). Expectancy, attention, and time. Cognitive Psychology, 41, 254-311.

Bregman, A. S. (1990). Auditory scene analysis: The perceptual organization of sound. Cambridge, MA: MIT Press.

Chun, M. M. (1997). Temporal binding errors are redistributed by the attentional blink. Perception \& Psychophysics, 59, 1191-1199.

Chun, M. M., \& PotTer, M. C. (2001). The attentional blink and taskswitching within and across modalities. In K. Shapiro (Ed.), The limits of attention: Temporal constraints in human information processing (pp. 20-35). Oxford: Oxford University Press.

Dalton, P., \& LaVIE, N. (2004). Auditory attentional capture: Effects of singleton distractor sounds. Journal of Experimental Psychology: Human Perception \& Performance, 30, 180-193.

Dalton, P., \& Lavie, N. (2006). Temporal attentional capture: Effects of irrelevant singletons on rapid serial visual search. Psychonomic Bulletin \& Review, 13, 881-885.

Duncan, J., Martens, S., \& Ward, R. (1997). Restricted attentional capacity within but not between sensory modalities. Nature, $\mathbf{3 8 7}$, 808-810.

Escera, C., Alho, K., Winkler, I., \& NäÄTÄNEn, R. (1998). Neural mechanisms of involuntary attention to acoustic novelty and change. Journal of Cognitive Neuroscience, 10, 590-604.

Escera, C., Corral, M.-J., \& Yago, E. (2002). An electrophysiological and behavioral investigation of involuntary attention towards auditory frequency, duration and intensity changes. Cognitive Brain Research, 14, 325-332.

Folk, C. L., Leber, A. B., \& Egeth, H. E. (2001, November). Capture at the fovea: Control settings and the attentional blink. Paper presented at the 42nd Annual Meeting of the Psychonomic Society, Orlando, FL.

Folk, C. L., Leber, A. B., \& Egeth, H. E. (2002). Made you blink! Contingent attentional capture produces a spatial blink. Perception \& Psychophysics, 64, 741-753.

Folk, C. L., \& Remington, R. W. (1998). Selectivity in distraction by irrelevant featural singletons: Evidence for two forms of attentional capture. Journal of Experimental Psychology: Human Perception \& Performance, 24, 847-858.

Folk, C. L., Remington, R. W., \& Johnston, J. C. (1992). Involuntary covert orienting is contingent on attentional control settings. Journal of Experimental Psychology: Human Perception \& Performance, 18, 1030-1044.

Franconeri, S. L., \& Simons, D. J. (2003). Moving and looming stimuli capture attention. Perception \& Psychophysics, 65, 999-1010.

Jones, M. R. (2001). Temporal expectancies, capture, and timing in auditory sequences. In C. L. Folk \& B. S. Gibson (Eds.), Attention, distraction and action: Multiple perspectives on attentional capture (pp. 191-229). Amsterdam: Elsevier.

JONIDES, J., \& YANTIS, S. (1988). Uniqueness of abrupt visual onset in capturing attention. Perception \& Psychophysics, 43, 346-354.

Julesz, B., \& Hirsh, I. J. (1972). Visual and auditory perception: An essay of comparison. In E. E. David, Jr. \& P. B. Denes (Eds.), Human communication: A unified view (pp. 283-340). New York: McGraw-Hill 
Large, E. W., \& Jones, M. R. (1999). The dynamics of attending: How people track time-varying events. Psychological Review, 106, 119-159.

Leber, A. B., \& Egeth, H. E. (2006). It's under control: Top-down search strategies can override attentional capture. Psychonomic Bulletin \& Review, 13, 132-138.

Lovelace, C. T., Stein, B. E., \& Wallace, M. T. (2003). An irrelevant light enhances auditory detection in humans: A psychophysical analysis of multisensory integration in stimulus detection. Cognitive Brain Research, 17, 447-453.

Maki, W. S., \& Mebane, M. W. (2006). Attentional capture triggers an attentional blink. Psychonomic Bulletin \& Review, 13, 125-131.

OdgaArd, E. C., Arieh, Y., \& Marks, L. E. (2003). Cross-modal enhancement of perceived brightness: Sensory interaction versus response bias. Perception \& Psychophysics, 65, 123-132.

Pashler, H. (1988). Cross-dimensional interaction and texture segregation. Perception \& Psychophysics, 43, 307-318.

Potter, M. C., Chun, M. M., Banks, B. S., \& Muckenhoupt, M. (1998). Two attentional deficits in serial target search: The visual attentional blink and an amodal task-switch deficit. Journal of Experimental Psychology: Learning, Memory, \& Cognition, 24, 979-992.

Raymond, J. E., Shapiro, K. L., \& Arnell, K. M. (1992). Temporary suppression of visual processing in an RSVP task: An attentional blink? Journal of Experimental Psychology: Human Perception \& Performance, 18, 849-860.

Soto-Faraco, S., \& Spence, C. (2002). Modality-specific auditory and visual temporal processing deficits. Quarterly Journal of Experimental Psychology, 55A, 23-40.

Soto-Faraco, S., Spence, C., Fairbank, K., Kingstone, A. Hillstrom, A. P., \& Shapiro, K. (2002). A crossmodal attentional blink between vision and touch. Psychonomic Bulletin \& Review, 9, 731-738.

SPENCE, C. (2001). Crossmodal attentional capture: A controversy resolved? In C. L. Folk \& B. S. Gibson (Eds.), Attention, distraction and action: Multiple perspectives on attentional capture (pp. 231-262). Amsterdam: Elsevier.

Spence, C., Ranson, J., \& Driver, J. (2000). Cross-modal selective attention: On the difficulty of ignoring sounds at the locus of visual attention. Perception \& Psychophysics, 62, 410-424.

Spence, C., Sanabria, D., \& Soto-Faraco, S. (2007). Intersensory Gestalten and crossmodal scene perception. In K. Noguchi (Ed.), The psychology of beauty and Kansei: New horizons of Gestalt perception (pp. 519-579). Tokyo: Fuzanbo International.

Stein, B. E., London, N., Wilkinson, L. K., \& Price, D. D. (1996). Enhancement of perceived visual intensity by auditory stimuli: A psychophysical analysis. Journal of Cognitive Neuroscience, $\mathbf{8}$, 497-506.

Theeuwes, J. (1992). Perceptual selectivity for color and form. Perception \& Psychophysics, 51, 599-606.

Theeuwes, J. (2004). Top-down search strategies cannot override attentional capture. Psychonomic Bulletin \& Review, 11, 65-70.
Vroomen, J., \& DE Gelder, B. (2000). Sound enhances visual perception: Cross-modal effects of auditory organization on vision. Journal of Experimental Psychology: Human Perception \& Performance, 26, 1583-1590.

WALKer, J. T., \& ScotT, K. J. (1981). Auditory-visual conflicts in the perceived duration of lights, tones, and gaps. Journal of Experimental Psychology: Human Perception \& Performance, 7, 1327-1339.

Watanabe, K., \& Shimojo, S. (2001). When sound affects vision: Effects of auditory grouping on visual motion perception. Psychological Science, 12, 109-116.

Wee, S., \& ChuA, F. K. (2004). Capturing attention when attention "blinks." Journal of Experimental Psychology: Human Perception \& Performance, 30, 598-612.

Welch, R. B., DuttonHurt, L. D., \& Warren, D. H. (1986). Contributions of audition and vision to temporal rate perception. Perception \& Psychophysics, 39, 294-300.

\section{NOTES}

1. Note that such attentional capture often appears to depend on the strategy of attentional allocation adopted by the observer, so that stimul will capture attention only if they fall within the observer's attentional set (e.g., Bacon \& Egeth, 1994; Folk \& Remington, 1998; Folk, Remington, \& Johnston, 1992), although this possibility is still the subject of much debate (e.g., Leber \& Egeth, 2006; Theeuwes, 2004).

2 . We chose to define targets and singletons by duration because the dimension of duration is meaningful in both vision and audition (e.g., Julesz \& Hirsh, 1972). We acknowledge, however, that duration is also an unusual feature, in that featural information is present only following the offset of the item in question (or, in tasks of discrimination between two possible durations, following the time at which the shorter item would be expected to offset). In other words, one cannot determine whether a stimulus is a target or a singleton from the moment it is presented. It is, therefore, possible that duration singletons might be processed somewhat differently from other types of singletons. We note, however, that several previous studies of attentional capture have used stimuli that cannot be identified from target onset (e.g., Dalton \& Lavie [2004, Experiments 5 and 6] used duration targets, and Franconeri \& Simons [2003] demonstrated attentional capture by looming stimuli).

3 . The data were analyzed as a function of singleton congruency (congruent vs. incongruent with the target), rather than singleton type (short vs. long), because the factor of singleton congruency was felt to be more informative with respect to the demands of the task than was the factor of singleton type (i.e., the question of whether singletons affected performance similarly, regardless of whether they were congruent or incongruent with the target, was thought to be of central importance).

(Manuscript received August 8, 2005; revision accepted for publication August 7, 2006.) 